\title{
Choosing between internal and non-internal R\&D activities: some technological and economic factors
}

\author{
Rajneesh Narula* \\ Senior Research Fellow \\ University of Oslo and the STEP group
}

\begin{abstract}
This paper evaluates some of the technological and economic factors that underlie the choice between in-house $R \& D, R \& D$ alliances and outsourcing. We recount the reasons for the growth in non-internal activities, and explain why these are not as prevalent for R\&D as other value-adding activities, and highlight that outsourcing is most often undertaken where multiple, substitutable sources are available. We then develop two frameworks. First, a static framework is developed, which evaluates the choice of mode based on a firm's distribution of competencies, and their strategic importance. Second, a dynamic framework is developed that demonstrates how the static framework differs depending on whether the firm is engaged in pre-paradigmatic, paradigmatic or post-paradigmatic sectors. We also consider the effect of new technologies being introduced to a firm's portfolio of competencies.
\end{abstract}

Key words: R\&D, innovation, alliances, outsourcing, technological paradigms

Corresponding address:

Dr. R. Narula

Centre for Technology, Innovation and Culture (TIK Centre)

University of Oslo

PO Box 1108 Blindern

N-0317 Oslo, Norway

Phone: +4722858719

Fax: +47 22858984

e-mail: rajneesh.narula@esst.uio.no

* Research funding by the Norwegian Research Council is gratefully acknowledged. Comments by Geert

Duysters, Keith Pavitt, Frédérique Sachwald, Gabriel Benito and Ivo Zander have helped in finalising this paper. 


\section{Choosing between internal and non-internal R\&D activities: some technological and economic factors}

Abstract This paper evaluates some of the technological and economic factors that underlie the choice between in-house $\mathrm{R} \& \mathrm{D}, \mathrm{R} \& \mathrm{D}$ alliances and outsourcing. We recount the reasons for the growth in non-internal activities, and explain why these are not as prevalent for R\&D as other value-adding activities, and highlight that outsourcing is most often undertaken where multiple, substitutable sources are available. We then develop two frameworks. First, a static framework is developed, which evaluates the choice of mode based on a firm's distribution of competencies, and their strategic importance. Second, a dynamic framework is developed that demonstrates how the static framework differs depending on whether the firm is engaged in pre-paradigmatic, paradigmatic or post-paradigmatic sectors. We also consider the effect of new technologies being introduced to a firm's portfolio of competencies.

\section{Introduction}

Over the past decade, there is growing evidence to suggest that firms no longer rely exclusively on their internal R\&D activities to maintain their technological competitiveness. This has been highlighted most recently by Veugelers (1997), Veugelers and Cassiman (1999), Hagedoorn (1996), Narula and Hagedoorn (1999), Archibugi and Iammarino (1999), among others. This development, it has been argued, in part reflects techno- and economicglobalisation, whereby there is an increasing similarity (and growing capital intensity) in the types of technologies across countries of the Triad. This is a result, inter alia, of growing cross-border competition, which has also led to reduced opportunities for profits, in the face of higher costs in maintaining technological assets to remain globally competitive (Archibugi and Michie 1998).

Our use of the term 'non-internal' is a deliberate one, and is intended to include both external activities (arms-length relationships such as licensing, R\&D contracts, outsourcing and other customer-supplier relationships) and quasi-external activity (such as strategic alliances, which is taken to include a myriad of organisational modes [Narula and Hagedoorn 1999]). Non-internal activities, apart from the obvious benefits of exploring new areas and instigating radical change, have the advantage of being a 'reversible' form of investment (Gambardella and Torrisi 1998). The capital needed is smaller, and the risks are substantially reduced, and in case of failure or organisational crisis, limited damage is inflicted on the primary operations of the firm. Nonetheless, the tacit nature of innovation, and the risks associated with loss of technological competitiveness, encourage a high level of in-house R\&D activity. 
Our starting point in the current paper is a synthesis of the seminal work of inter alia Teece (1986, 1996) and Granstand, Patel and Pavitt (1996). We develop an understanding of some of the most significant technological factors that determine the kinds of non-internal R\&D activities undertaken by multi-technology manufacturing firms. The choice between internal and non-internal $R \& D$ activities is determined by (a) distribution and kinds of competencies that the firms possesses, (b) the evolution of individual technologies, and the changing characteristics of the technology as it progresses from a new technology to a mature one, (c) strategic and economic issues relating to the competitive environment.

Although the paper primarily describes a conceptual framework to understand how a firm decides between internal, external, and quasi-external technology development, it has been refined and synthesised on the basis of a number of interviews with 32 senior R\&D managers of European-based technology-intensive firms. We have illustrated our arguments with anecdotal evidence based on these interviews. Appendix A gives details of our interview methodology and limitations of the data.

Understanding the reasons for the success and failure of cooperative activities has farreaching implications from both a managerial and policy perspective. The 'right' mix of internal and non-internal R\&D activities can prevent firms not only from over- or underinvesting in $\mathrm{R} \& \mathrm{D}$, but also help to maintain their long-term competitive position.

The next section discusses some of the relationships between the multi-technology firm and the growth of non-internal R\&D. The third section attempts to differentiate between alliances and outsourcing. The fourth section examines the static issues underlying the choice of mode and the distribution of competences. We then discuss the evolution of technologies, and the dynamic choices that firms must make. The final section develops some conclusions, highlights the caveats, and develops an agenda for future research.

\section{The growth of the multi-technology firm and non-internal R\&D}

The growing need for firms - particularly in technology intensive sectors - to have multiple technological competences is by now axiomatic. Several contributions, notably by Granstand and associates (see e.g., Granstand 1998, Granstand, Patel and Pavitt 1996) have noted the growing technological diversification of companies, and more recently, that this is associated with a reduction in product diversification over time. Even where products are mono-technology-based, the processes used to manufacture them often utilise several technologies. Furthermore, within a given technology, there are several technological paradigms at play, as firms base products on the current dominant design, yet develop nascent 
technologies with the long-term intention of replacing the current technology with a new dominant design.

The increasing cross-fertilisation of technologies across disciplines and resultant broader portfolio of competences has become fundamental to the competitiveness of technology-based firms. There has also, however, been a concurrent increase in competition, due, inter alia, to the liberalisation of markets, and the reduction of transaction and transportation costs. This has led to a decline in the profit margins due to increased crossborder competition and barriers to entry (Buckley and Casson 1998). As such, the increased costs of requiring more technological competences is not offset by greater profits, but quite the opposite. In addition, $R \& D$ in new technologies has been seen to be increasingly capitalintensive. So, the need to reduce costs (and maintain profits), while maintaining the firm's technological assets has become an important managerial balancing act.

The attempt to understand the reasons behind a firm's choice between external and internal technological development is not new. The work of Teece (1986) presents a pioneering analysis of this issue, which builds on work by Abernathy and Utterback (1978), Dosi (1982) among others, and further developed by Pisano (1990), Arora and Gambardella (1990) and Henderson and Clark (1990). More recent work include Granstand et al (1996), Granstand (1998), Nagarajan and Mitchell (1998), Veugelers and Cassiman (1998), Croisier (1998), Lowe and Taylor (1998), Tidd and Trehwalla (1997) and Gambardella and Torrisi (1998).

One of the reasons attributed to the growth of non-internal activity has been the decline in transaction costs for external or quasi-externalised relationships, relative to complete internalisation, not just for $\mathrm{R} \& \mathrm{D}$, but for most aspects of value adding activity. As firms have responded to this new scenario, there has been a dis-integration of certain firms in particular industries, as they seek flexibility and lower risk, which have hitherto preferred vertical integration. Some notice has been made of the process of dis-investment, that, appears to have become quite commonplace during the last decade (Benito 1997). However, this has happened only to a limited extent in the case of R\&D. (estimates suggest that between 10 and $15 \%$ of agreements involve $\mathrm{R} \& \mathrm{D}$, although this figure has increased three fold since the $1980 \mathrm{~s}^{1}$ ). Why do firms demonstrate a lower propensity to use non-internal sourcing for R\&D? The reasons for its relative lack of popularity have to do with the nature of the innovation process. First, because the innovation process is highly uncertain, and there are considerable

\footnotetext{
${ }^{1}$ These estimates are based on the results from two different surveys, Culpan and Costelac (1993), and Gugler and Pasquier (1996).
} 
costs in negotiating and enforcing contracts. Second, the large tacit component of innovation means that through external sourcing, firms are only able to get codified results, not the accumulated, person-embodied skills. Third, the partially-public good nature of technology also means that there is considerable opportunity for technological leakage and/or opportunistic behaviour by collaborators (Veugelers and Cassiman 1999). Fourth, appropriability of innovation varies widely, both by country and by industry, which further increases the possibility of loss of key assets. In other words, the uncertainty of the process, the high costs of transaction and risk of losing strategic assets crucial to the survival of the firm inhibit non-internal activity. As Nagarajan and Mitchell (1998) point out, the advantages of internal R\&D activity are also its limitations. Firms are path-dependent, and find it costly to break away from existing routines towards radically new or different concepts. There are additional costs involved in switching trajectories which may impede organisational change and exacerbate the level of uncertainty and therefore economic risk ${ }^{2}$.

Can the growth of non-internal R\&D activity be explained simply by imperfections in the strategic and economic organisation of internal R\&D? The answer is complex, and is associated with our use of the term 'non-internal' to include both external activities (armslength relationships such as licensing, R\&D contracts, outsourcing - and other customersupplier relationship) and quasi-external activity (such as strategic alliances, which are mostoften undertaken between competitors). Non-internal activities, apart from the obvious benefits of exploring new areas and instigating radical change, have the advantage of being a 'reversible' form of investment (Gambardella and Torrisi 1998). The capital needed is smaller, and the risks are substantially reduced, and in case of failure or organisational crisis, limited damage is inflicted on the primary operations of the firm.

Fully external activities are not novel - it has, for instance, been accepted for quite some time that universities and state-subsidised institutes represent an important source of basic research for commercial firms. Indeed, it is the development of horizontal collaboration between competitors that is relatively new, particularly in strategic technology partnering, where the growth has been almost exponential (see e.g., Hagedoorn 1996). Nonetheless, as the survey by Tidd and Trehwalla (1997) illustrates, external sourcing of technology remains a larger phenomenon than strategic alliances. However, it is difficult to quantify the differences in growth between external and quasi-external $\mathrm{R} \& \mathrm{D}$, because it is hard, if not impossible, to estimate the potential value of quasi-external agreements to the firms involved

\footnotetext{
${ }^{2}$ This line of reasoning is well-developed - see e.g., Nelson and Winter (1982) Cyert and March (1963), Mitchell and Singh (1996) among others.
} 
(Narula 1999). First, because R\&D is tacit, and has a long-term horizon: the value of the research cannot be estimated ex-ante. Even where there is a short-term horizon and the objective is non-tacit (say, establishing technological standards), and the resulting output is patentable or licensable, technologies cannot always be correlated with products (and thus sales). Second, even where firms can place a value on an agreement, they have no incentive to make such information available, either to each other, or to the public. The evidence from our interviews indicates that in terms of expenditures, firms spend between 15 and $25 \%$ of the R\&D budget in technology outsourcing, and 5 to $10 \%$ in collaboration, although the value of the latter may well be greater, because of the strategic importance of the areas where alliances are undertaken. At the same time, as we discuss below, it is relatively easy to determine the value of outsourcing. It is important to note that alliances are a complex organisational form and require considerable resources to maintain collaborative activity, compared with more arms-length agreements such as outsourcing. Tidd and Trehwalla (1998) for instance, note in their survey of Japanese and British technology acquisition strategies, that only $13 \%$ of their firms considered alliances as an significant technology source. It is worth noting too, that horizontal alliances, in the sense of collaboration between competitors is a relatively small phenomenon. Firms partner with competitors only with the greatest of caution, and only on specific and carefully defined projects.

\section{Standardisation, cost and industrial organisation}

The growth of non-internal activity has in part occurred because of a redefinition of the boundaries of the firm (in the Coasian sense) such that it is increasingly cheaper to undertake such activities outside the firm. Clearly this has not happened on an equal basis for quasi-external and fully-external agreements, particularly for R\&D activities. As we have highlighted earlier, firms in our sample engage in three times as many outsourcing agreements than they do alliances. The answer to this discrepancy lies in a simple fact: standardisation of technologies across borders due to technological convergence has led to a decline in the production costs of clearly defined inputs to the value-adding process, as well as the transaction costs associated with their acquisition. By 'clearly-defined' we refer to codifiable, non-tacit inputs to the production process.

Here it is cogent to distinguish between vertical-chain-related activity and horizontal activity. The growth of vertical relationships (essentially customer-supplier agreements) is governed by the ability of firms to monitor the quality of external suppliers due to improved communications. The convergence of technological standards in 'generic' production 
technologies creates alternatives to direct control, since quality requirements are similar, and if these inputs do not meet specifications the shortcomings can be quickly identified and addressed without costly time delays. Horizontal alliances, particularly with competitors, are generally undertaken for strategic reasons, with cost issues playing a secondary role (Narula and Hagedoorn 1999). The principal reasons for alliance activity is to maintain closer control of the activities of the collaborator, and to enhance and monitor the transfer of technology between the partner. If the knowledge to be transferred is well-defined and available from multiple sources, complex organisational cooperation modes such as alliances are unnecessary $^{3}$. It follows, therefore, that $R \& D$ alliances take place in diametrically opposed circumstances than outsourcing. The relationships in horizontal agreements tend to reflect a more complex strategic intent, and arms-length transactions do not in general provide this.

External acquisition of technology is most easily done when the technology behind the product is codifiable and standardised and for which multiple non-distinguishable sources of these inputs are available. The same argument holds true for R\&D activity, since R\&D output is partly tacit, externalisation of $R \& D$ means that the firm only gets the codified results, not the accumulated person-embodied skills. As has been noted elsewhere, even where firms outsource, they maintain a minimum level of in-house capacity in those technologies in order to decipher and utilise them (Veugelers 1997). In other words, R\&D outsourcing is only undertaken where doing so is cost-effective AND does not threaten the competitive advantages of the company. Having a single source or single buyer may prove to be most cost-effective, but it is generally accepted that low costs do not always translate to the best technology. Moreover, dependency on a single supplier (or a single customer) represents a bottle-neck, and the problems associated with a monopolistic/monopsonistic pricing. Furthermore, there are positive technological externalities of multiple sources of innovation. Pratt and Whitney, for instance, has several suppliers of turbine intakes, even though they have in-house design and manufacturing facilities. External bids are always sought for new products from all parties, as a way of establishing a benchmark for quality and costs. Innovations from all the various suppliers are all absorbed into the final product.

Where either the know-how for the inputs is unique and non-substitutable (either because it is proprietary and firm-specific, or it is location-specific), or it is tacit and noncodifiable, cost based issues become less relevant, and strategic (and resource) considerations, (such as core competences) take on greater importance. We examine these issues separately.

\footnotetext{
${ }^{3}$ However, there are often other factors why firms may decide to undertake alliances. For instance, there may be several other alliances between firms in other technologies, for which alliances maybe necessary.
} 
When the input necessary is unique. If the input is firm-specific (for instance, Windows operating system), the cost becomes less relevant ${ }^{4}$ and the resource availability becomes important. The development of new software is generally dependent on the features to be incorporated into the next version of Windows. In these cases, the relationship between the software firm and the Microsoft is much more strategic, and requires certain resources to be devoted to the interaction between the two firms. As such, the software firm is involved in an alliance which determines the long term product-market positioning of at least one of the firms. Where the resource is not completely internalised by the firm, but is particular to a location or a region, a similar scenario applies, only that this affects production costs more than transaction costs. There is a well-developed literature on the role of national (and regional) systems of innovation and their influence on the location of companies (see e.g., Edquist 1997, Lundvall 1992). This may either be to benefit from socio-technological inputs such as educational establishments, infrastructure, or simply to exploit economies of agglomeration, and to seek possible spillovers. Where such inputs are unique, that is, the resource is unavailable elsewhere, and proximity to its source is necessary, the choice of location is production-cost-independent (Sachwald 1998). It is to be noted that although the cost issue may be secondary in the case of an immobile location-specific factors, it does not mean that it is unimportant ${ }^{5}$. Since these resources are crucial to the survival of the firm, they take on a strategic importance that clearly outweighs any cost-savings that might derive from outsourcing. Where the input is unique, some of this uncertainty can be reduced by considering quasi-hierarchical agreements such as alliances.

Tacit or non-codifiable inputs. Because of their nature, certain inputs to the value adding process are less clearly defined. This is especially the case with most innovatory activities, but is also true for specialised resources where innovation is not involved, but the final product is tacit in nature. Therefore, it is much more difficult to outsource these aspects of the production process, because it is hard to specify the quality of the resource. Identifying a supplier who would be able to produce it may be difficult, since its nature is difficult to specify ${ }^{6}$. Where the product has a high level of tacitness, property rights will most likely be

\footnotetext{
${ }^{4}$ Although there exists a imperfect substitute (Macintosh). For a firm that wishes to enter the Wintel market, however, there is no choice.

${ }^{5}$ Take for instance the case where proximity in necessary, such as in a customer-supplier agreement that requires just-in-time delivery. Where cooperative agreements are undertaken in such a case, such decisions are mainly cost-based.

${ }^{6}$ Cowan and Foray (1997) argue that while codification is never complete, the extent to which knowledge is codified depends on the costs and benefits of doing so. Although new technologies have lowered the costs of codification, certain kinds of knowledge are too expensive to codify, simply because the information is useful to only a small number of users.
} 
unclear. In other words, the market for such resources are hard to establish. Where such supplier firms do exist and property rights are well-defined, they are able to charge monopoly rates, since they have access to unique resources, and price comparisons are thus impossible. In addition though, closer cooperation than might be provided by networks is also necessary, because firstly, the contracting firm is itself unsure of the nature of the resources, and must monitor the activities of the supplier firm more closely. As Cantwell and Santangelo (1999) discuss, greater tacit and uncodified knowledge require closer, face-to-face interaction. Secondly, the customer would like to avoid the potential loss of his assets to the supplier company. In such cases, outsourcing is the least preferred option.

\section{Distributed competences and the choice between internal and non-internal activity: a static view}

The technological competencies and assets of a firm can be classified into several distinct kinds. Not all activities are equally crucial to the competitiveness of the firm. Nagarajan and Mitchell (1998) propose a two way classification of core and complementary technologies, while Granstand et al (1996) view these as being of four types. We have utilised the Granstand et al framework that the competences of technology based firms can be viewed as being of four types (figure 1).

\section{*****FIGURE 1 ABOUT HERE****}

Firms have distinctive competences, which command a high share of technical resources of a company. These form the 'core' of the firm, which define the technological profile of the firm and its competitiveness. Then there are the niche sectors, which are technologies which the firm possesses some level of expertise, but these areas are intrinsically small in terms of their profile, and in terms of the resources they command. These technological fields are generally complementary to their distinctive competencies. Marginal/peripheral technologies are sectors which were important to the firm in the past, or are expected to become important in the future, in which limited resources are invested, and where the firm has no distinct technological advantages. Finally background competences enable firms to coordinate and benefit from technical change in the supply chain, which are essential to the competitiveness of the firm, and it ability to efficiently utilise its other, more 'crucial' competences. Although these are equally crucial, and significantly determine the 
competitiveness of a firm, they only utilise a small percentage of the firm's technology resources. They are, however, an important part of the firms technological assets.

\section{****FIGURE 2 ABOUT HERE****}

We postulate that Figure 2 shows how the choice between in-house $R \& D$, alliances and outsourcing relate to the 4-way classification of Figure 1 from a static perspective. Firms in our interviews were asked to discuss the importance of their technological activities within this 4-way classification, in terms of competencies and technological assets. Then, their primary internal, external and collaborative efforts were identified according to the areas of in-house R\&D, technological collaboration and outsourcing. Figure 2 presents the generalised results of our interviews. Firms will, ceteris paribus, prefer to undertake innovative activities in their distinctive competences (quadrant I) through in-house R\&D. Although there is considerable overlap in the case of quadrant III and IV (figure 2), broadly speaking these competences are strategically less significant, and can be undertaken through alliances However, the strategic importance of these technologies determines to what extent their development can be externalised. This, in turn, is determined by the extent to which the technology is tacit, the extent to which collaboration is required to utilise it, and to what extent the partners activities need to be monitored.

Background competences (Quadrant II) are, by and large, the area where outsourcing is primarily used. In general, it would seem firms prefer to undertake research in their distinctive competencies in-house as much as possible. There is, however, considerable overlap in the use of in-house $\mathrm{R} \& \mathrm{D}$ and alliances for niche competences, and between outsourcing and alliances in marginal/peripheral competencies. In general, there is considerable idiosyncratic behaviour of firms. Take for instance the case of 'firm A' (see appendix A for brief description), which considers alliances in their niche sectors unacceptably risky:

"These competencies are too important to us....we have spent many years building our strength in these sectors...frankly we have world class competences......I am loathe to consider letting anyone near our technology. We only use alliances [in these areas] if we have to."

The differences in the propensity varied according to industry and size (discussed further in the next section). The use of alliances in connection with niche sectors was, in general, associated with firms that had limited R\&D facilities and/or considered that there was 
a large technological gap between their technological competencies and the market leaders. The issue of size seems to be a very significant one. Firms with limited resources considered alliances as a way of extending their technological competences. For instance, one medical equipment manufacturer ('Firm A') did not have the resources to invest in the next generation of displays. Although LCD technology has become more mature over the last 5 years, it remains capital-intensive, and proprietary technology at the forefront rests with a handful of companies. It therefore sought an alliance with a US company which is a market leader in medical equipment, many times their size. However, the US firm did not currently compete with them in their particular product segment, and agreed to share the technology and to distribute their products in the US. As a manager pointed out,

"It's a risk [to ally with such a large player], but the cost of developing our own display systems would use up almost our entire R\&D budget for a couple of years... and our old product range was [beginning to look] old. [They] have the technology lying around, because they have more people in their R\&D facilities than we have in our entire company... [if they wanted to] they could buy us out, whether we had a partnership with them or not [so it doesn't matter whether or not we partner with them]."

\section{****FIGURE 3 ABOUT HERE****}

Figure 3 illustrates the distribution of competences for 'firm B' which represents an amalgam of the competencies of four measuring and control equipment manufacturers. The decision to use alliances is determined by additional issues apart from the protection of competitive advantages. Firm B's scale of production is in the thousands, far below the minimum efficient scale for active component manufacture. The manufacturing and design of specialised active components is therefore an area where it is impractical for the firm to maintain in-house facilities. It makes economic sense, therefore, to provide the performance specifications to a specialised component manufacturer. Nonetheless, because this is an input that is crucial to the competitive advantage of the firm, it is designed in close cooperation with the engineers in firm B.

The manufacture and design of printed circuit boards was left entirely to external firms, and completely outsourced. Apart from quality control checks when the completed boards were delivered, no attempts were made to monitor or control PCB production and design. Likewise casings, mountings, and the design of power supply units (which have become highly standardised and are now essentially off-the-shelf products) were also 
completely outsourced. For all these products there were several suppliers available. As a principle,

"we use more than one supplier, our products are based on several boards. Each supplier produces only one board, because we don't want any supplier to have access to our complete product. We might be able to get a lower price, but we don't want to be in a position that the supplier is able to become a competitor. Nondisclosure agreements aren't enough."

As we have earlier suggested, all the managers interviewed agreed that the volume of outsourcing has expanded considerably over the last two decades. They considered that the growth of outsourcing has a lot to do with the process of globalisation, particularly in terms of a) ease of enforcement of contracts and the ability of firms to monitor the activities of suppliers due to ICTs, and b) the increased competition due to the entry of several emerging Asian economies in technology-intensive sectors.

"The world is a much smaller place...we travel to visit our major suppliers in Taiwan and America at least three or four times each [every year], and they ship us samples by DHL for us to test."

It is worth noting that not all firms based their decisions on rational economic or strategic issues. One medium sized firm ('Firm A'), had, in the early 1990s, started manufacturing trauma and intensive-care equipment. As their first generation products reached the end of their life cycle by 1997, the firm was faced with a dilemma. It had continued to maintain a relatively low R\&D intensity (and a correspondingly small in-house R\&D staff) despite adding more high-tech products, and therefore decided to completely outsource its new generation of products, but in order to maintain what they saw as their competitive advantage, the head of $R \& D$ decided to outsource the design and manufacture of different sub-assemblies separately, co-ordinated by firm A's research lab. Partly because the manufacture of the sub-assemblies was done by different contractors than the design, and there was little, if any, direct coordination between the design and manufacturing teams, the final assembled products failed to work within specifications. The product release was delayed by a year, as the in-house $R \& D$ had to engineer changes, modification and further testing. Firm A has now responded by establishing a policy against outsourcing of any aspect of the design and manufacture process. It has now established a strategic alliance with a 
competitor (which has a different geographic focus) to develop its next generation of products.

A cautionary attitude towards alliances is widespread, especially among smaller firms. 'Firm D' outsources almost all aspects of its manufacturing activities, and represents an extreme approach. They have a policy against strategic alliances. It does, however, invest considerable time in selecting supplier firms, so that their customer-supplier relationship is very close-knit. Small supplier firms are selected so that there is little chance of their being able to reverse-engineer their product, and of becoming a competitor. Long and complex contractual agreements are made with each firm which have non-performance penalties and clauses, and the production activity is monitored regularly by visits from the R\&D department of firm D.

As we have earlier emphasised, there are considerable variation by firms, due not just to differences in strategy and history, but also by industry. The next section discusses how technologies evolve, and how this changes the choice of organisational mode over time.

\section{The dynamic view: The evolution of technological paradigms}

We turn our attention to the dynamics aspects, and in particular the issues relating to the evolution of technologies, and its effect on the decision to internalise innovatory activities. Our primary emphasis is on explaining how the choice of mode is affected by (a) the stage of evolution of the technological paradigm, and (b) how the introduction of new innovations to the existing portfolio of a firm affects its static choices highlighted in the previous section. Our discussion of this evolution is not new, and builds on earlier notions of this process developed by Dosi (1982) among others. Teece (1986, 1996), in particular, has utilised these ideas to build an framework regarding its effects on the internalisation issue, upon which we build.

As Teece (1986) has argued, the maturity of the technology, and its characteristics, determines the extent to which the innovation process can be internalised. Obviously, every technological trajectory of each individual firm is unique, since the innovation process is path-dependent on previous innovation. In other words, there are cognitive limits on what firms can and cannot do (Pavitt 1998). Nonetheless, once a 'dominant design paradigm' has been established, firms innovate around this paradigm, with the intention of improving it, or replacing it. They therefore are dependent on the last-best (i.e., state-of-the-art) innovation. If a firm is engaged in developing an innovation in a given technological paradigm, it must 
strive to improve (or at least take into account) not its own last-best innovation, but the lastbest innovation that has been patented, or that is the dominant design on the market ${ }^{7}$, even if this was created by another firm. Thus its path-dependency is always tempered by the stateof-the-art, and this means that roughly speaking technological trajectories of different firms within any given technological paradigm are similar. At the risk of over-simplifying, technologies (within a given paradigm) evolve through different stages, and these can be viewed as being determined by two factors: the level of uncertainty in the nature of the technology and the speed of technical change within it. These two factors also determine other issues which affect the internalisation or externalisation of $R \& D$, such as the level of appropriability. Figure 4 places these two dimensions into context, using a $2 \times 2$ matrix. The arrows indicate the typical time-trend of evolution of a technology, from quadrant A to D.

\section{****FIGURE 4 ABOUT HERE*****}

The concept of uncertainty within the innovation process is well-understood, and we shall not delve into it in detail. In general, the newer the sector, the closer it is to 'basic research' in the sense that the outcome of the research will lead to fundamental changes in knowledge, rather than technology. Such 'blue sky' or pre-paradigmatic research generally has a higher level of uncertainty than research within a defined paradigm. As the technology becomes diffused and codified (and a paradigm defined), the level of uncertainty drops.

The rate of technical change is determined not just by the level of uncertainty of technological change, but the number of possible directions in which it can develop, because there are multiple alternatives to any innovation. Thus, while technological change may not always be perceptible or discrete, it is continuous. It is not however determined by one company or idea but numerous path-dependent solutions being developed independently by several innovators or would-be innovators. In other words, while the innovation being developed by one company is unique to it, it represents one of many possible solutions to a technological hurdle. Whether it belongs to the dominant paradigm is irrelevant, because modifications to the dominant design continue, as well as attempts to supplant it with a new design.

Although the rate of technical change is not linearly related to uncertainty, it is nonetheless determined by the reduction of uncertainty, as a dominant design is established.

\footnotetext{
${ }^{7}$ Numerous examples of technically sub-optimal innovations defining the technological trajectory exist (e.g., Betamax vs. VHS, Macintosh vs. PC). Perhaps the best documented example is of the QWERTY keyboard (David 1985)
} 
However, as we have earlier emphasised, in addition to innovation within the dominant design, there are attempts to supplant the dominant paradigm with new paradigms. These may occur directly, or because of changes in complementary technologies. As Teece (1986) observes, complementary technologies may evolve together, and affect each other, depending on whether the technologies are co-specialised, specialised or generic. We illustrate this point by taking the example of the further miniaturisation of integrated circuits, and two related technologies: that of fabrication technology and the materials technology, which are cospecialised technologies (developments in one restrict and/or define developments in the other). Within the existing fabrication technological paradigm, the solution is to use lower wavelengths in the etching process. The current technology relies on lens-based tools which use deep ultra-violet light, which may be regarded as generic and paradigmatic. Markets for this innovation already exist, and these markets operate efficiently. The nature of the property rights of innovation are clear. Technological change is rapid, and the dominant paradigm is well-established. Such a technology could be classified in quadrant $\mathrm{C}$ in Figure 1. However, simply reducing the wavelength further to get further miniaturisation is a limited option, since traditional optics become opaque below certain wavelengths. There are at least four different technological trajectories being proposed, and being pursued by various consortia. IBM and Canon plan to replace this with X-rays, while Siemens is working on ion-beams. Intel, Motorola and AMD are working with soft-X-rays ${ }^{8}$. The technology is undefined, but change is rapid, because the technologies are clear, and the outcome desired is a matter of 'when' and 'who' rather than 'if'. It only remains to be seen which of these technological solutions will be dominant. Such a technology is in quadrant B, and will move rapidly into a paradigmatic state (quadrant C).

However, technologies do not necessarily evolve endogenously. Complementary and related technologies also evolve, and can change the distribution of firm's competences, especially where new innovations or completely new technologies are introduced in the market place. Teece's distinction between systemic and autonomous innovation is critical here. Autonomous innovations fit comfortably into existing technologies and competences, while systemic innovations significantly effect the existing competences of a firm, and the distribution of its competences. For instance, a company engaged in the production of fabricated metal equipment will find an innovation in adhesive technology to be peripherally related to its industry, since improvements in epoxy-based adhesives represent an option to

\footnotetext{
${ }^{8}$ Webb, Jeremy 'Crashing the Barriers', New Scientist, 7 November 1998, pp 42--47
} 
welding, and at may best represent a niche competence. It does not, however, systemically affect its operations, nor is likely too, even if adhesives eventually replace welding.

In the case of integrated circuit fabrication, developments in new materials for insulation materials, semiconductors and micro-wiring represent possible systemic innovations. There are limitations associated with making chips smaller with the current materials, and this requires a complete change of technological paradigm to other materials such as copper, plastics and gels from aluminium and silicon dioxide, but these are unknown (and therefore pre-paradigmatic) areas. Copper-based wiring technologies are also in quadrant B, because although they have been developed, they are still highly tacit and preparadigmatic. Plastics and gels as insulators are in quadrant $\mathrm{A}$, because they are as yet impractical, and little further than promising concepts.

Differentiating between quadrant $\mathrm{A}$ and $\mathrm{B}$, is difficult, because they are 'new' technologies and new trajectories within technologies. These industries share certain characteristics: neither the dominant technological trajectory is known, nor indeed the objective. The technology is highly tacit, and not necessarily commercial. It is important to emphasise that we are speaking of technologies and practical research outcomes, rather than products. Take the case of battery technology. Although there has undoubtedly been vast improvements in the technology, the basic paradigm underlying stored electrical energy has not changed dramatically in the 200 years since Volta. There is slow technical change taking places within the old technological paradigm - that of chemical batteries. It would thus be in quadrant D. There are new technological trajectories (such as fuel cells), but because they are new and commercially unproven, the outcome of the selection process is unknown, so it is impossible to determine ex ante whether the research outcome is in quadrant A or B. Which of these trajectories will be the commercially successful one is also unknown. So until a trajectory becomes 'established' as a dominant one, it is uncertain whether technical change is rapid or not. What we are trying to suggest here is that technical change and innovation cannot be viewed from an entirely scientific perspective, but also from its viability from a commercial point of view.

At the other extreme of technical change are most metal technologies (steel, aluminium, etc) - these are slowly-evolving and mature technologies which demonstrate minor but consistent innovations over time, and can be regarded as post-paradigmatic. Thus they are located in Quadrant D. The technology is to a great extent codifiable, widely disseminated, and the property rights are well-defined. Innovation is rarely patentable in these technologies, where applications development account for most innovatory activity. 
Competition shifts towards price, economies of scale, and downstream activities in order to add value, as the original product is priced as a commodity.

\section{Dynamic aspects of choosing between in-house R\&D, alliances and outsourcing}

How does this relate to the use of non-internal modes of technology sourcing? It is clear from the preceding review of fundamental concepts that the choice between non-internal and internal R\&D (and within non-internal activities, between outsourcing and alliances) is a complex process. We focus on two main questions. First, how does the use of non-internal sourcing vary by industry? Second, how do technologies change over time, and how does this affect the use of internal and non-internal sources?

The main issue here would seem to be the stage of evolution of the distinctive competences of the firm. This is the reason that there is considerable overlap in figure 2 between in-house $\mathrm{R} \& \mathrm{D}$, outsourcing and alliances. Take the case where the products and the distinctive technologies that underlie it are pre-paradigmatic, that is, they are in quadrant $\mathrm{A} / \mathrm{B}$. technologies that relate to it are likely to be tacit, and competition to create a de facto standard and establish a paradigm is high. A firm in such a market segment will try, as much as possible, to keep its niche and distinctive competences in-house, but support these with alliances wherever necessary, particularly for strategic reasons. It will seek to establish alliances with competitors to create standards, as well as with suppliers to establish a dominant design. Even in marginal and peripheral sectors of competence, it is important to develop long-term relationships with firms so as to establish these firms' products as dominant designs. The establishment of a dominant design is also enhanced by the entry of number complementary and peripheral products, which depend on compatibility. Take the example of the hand-held computer (HPC) manufacturer, Psion. In order to establish its operating system (Symbiant) as the standard, it has established alliances with the four largest mobile telephone manufacturers (Nokia, Ericsson, Motorola and Matsushita). The merger of mobile telephony with computing is as yet (circa 1999) a nascent idea, and it represents a peripheral technology to both parties, but one which all concerned believe will dramatically change their distinctive competences. The rival operating systems ${ }^{9}$ and designs have each been engaged in the same attempt to create a 'critical mass' of peripheral device manufacturers and to establish

\footnotetext{
${ }^{9}$ Microsoft is promoting its Windows CE as the standard, both for HPCs and PDAs, but unlike Psion, does not manufacture its own hardware. It has established alliances with AT\&T, Philips, Sharp, Hewlett Packard, among others. A rival operating system is offered by $3 \mathrm{Com}$, which only works with PDAs, and which they have preferred to keep proprietary.
} 
standards. However, the battle is not simply over operating systems, but also between hardware systems.

The preference, however, for in-house $R \& D$ for distinctive and niche competences, supported by alliances, is only where radical changes or new technologies might have a systemic effect on their distinct competences. Figure 5 gives the decision tree that would ordinarily face a company that has to decide how to allocate resources for a new preparadigmatic technology. For instance, where the new technology has an autonomous effect on its competitiveness - in the case of Psion, say, new battery technology (slow technical change) - and multiple substitutable sources are available, outsourcing is undertaken (see figure 5). However, standards for mobile telephony and related technology are central to Psion's competitiveness. This is an area where standards are almost paradigmatic (only two set of standards remain in contention), but not quite (quadrant B). It will have a systemic effect on its existing assets, so the firm is obliged to conduct in-house R\&D in combination with alliances (figure 5).

*******FIGURE 5 ABOUT HERE*******

For firms for whom core products technology is in quadrant $\mathrm{C}$, where a dominant paradigm is established, more technologies can be outsourced, and more areas of niche competences can be undertaken though alliances Figure 6 gives the corresponding decision tree that firms face. However, there are two aspects to engaging in alliances in quadrant $\mathrm{C}$ technologies. On the one hand, the technology is fast-evolving, and although nominally property rights protection exists, patenting is often a limited source of competitive advantage given the rapidity of change. Firms do not always have recourse to patenting as a means to protect new and rapidly evolving technologies, and must rely on secrecy, or on lead-time ${ }^{10}$, or by co-inventing with a potential competitors (Levin et al 1987). As noted in a survey of European firms, the propensity to patent new products averaged 35.9\% across sectors, and $24.8 \%$ in process innovations (Arundel and Kabla 1998). The need for secrecy, combined with the rapidity of change means that, where the technology is a niche or distinctive one, ceteris paribus, firms will choose in-house $R \& D$. On the other hand, the rapidity of technical change and the high costs of innovation may lead to alliance activity. Take the situation where two firms in the same industry are pursuing an important new breakthrough independently. Neither can be certain that they will win the race to innovate. As such, it may be in their best

\footnotetext{
${ }^{10}$ Where the innovator attempts to get the product to market before competitors, with enough lead time, such that by the time they imitate, the first innovator has progressed to a newer and better product.
} 
interest to collaborate, thus ensuring both that they are jointly 'first': half a pie may be considered better in conditions of uncertainty while there is a probability that there may be none at all (Narula 1999).

*******FIGURE 6 ABOUT HERE*******

Technologies also evolve in their importance to the firm. Figure 7 shows several technologies for firm B which shifted in importance over time, and moved from one kind of competence to another (illustrated by arrows). For instance, until recently, PCB design was done in-house. The design of double-sided printed circuit boards had required a high level of skills, but recent software design products for PCs had become so powerful, and the knowledge to do so quite diffused, that this was no longer a complex task. Thus, design could now be outsourced.

*******FIGURE 7 ABOUT HERE*******

Once a dominant design establishes itself, a technology that may have been a distinctive competence may in fact be peripheral, or even background. For instance, in the case of firm B, in the early 1980s, the operating system was considered a crucial technology and a distinctive competence (figure 7). This was a technology that was fiercely guarded, and on which almost $20 \%$ of its R\&D resources were invested. By the late 1980s, it had become a niche sector. It had become easier to hire programmers skilful in OS development, and although the OS was still seen as crucial, fewer resources (less than 10\%) were devoted to itessentially a niche sector. By the late 1990s, although the OS remains crucial to their competitiveness, they no longer have to maintain a proprietary OS, since a dominant design (Windows) exists, for which considerable off-the-shelf software is available, a high level of competence at developing customised versions of the OS and software can be easily (and cheaply) accessed from consultants. Less than $5 \%$ of their resources are spent on software development as a whole, and most of their requirements were either outsourced, or developed within an alliance. There are now no R\&D staff that are engaged full-time in software design or development. PCB design has also demonstrated a similar shift (see figure 7), going from a niche technology to a marginal one, while PCB manufacture has progressed from a niche competence to a background one, and is now completely outsourced.

It is important to note that it is not always possible to determine ex ante whether an innovation will have a systemic effect of an autonomous one. Take the situation where a new technology may threaten the distinctive competences of a firm, but the area of innovation is 
pre-paradigmatic (in quadrant A) and the potential benefits or effects on current competences are still highly uncertain- say gene therapy for a pharmaceuticals company. Such an area of innovation can be pursued independently from other innovations, it will more likely undertake this through non-internal means. Where the expected benefit of the new area of research is still unknown, the firm will not be interested in investing large internal resources, until the potential benefits are more tangible, a risk-reduction strategy through collaboration is most often viable (Mitchell and Singh 1992). However complete externalisation is impossible, since the nature of the output is unknown. In the case of biotechnology, large pharmaceutical firms rresolved this by acquiring a minority stake in small, start-up biotech firms. This gave the large firms an 'option' to acquire (and thus internalise) or otherwise control the research output of the small firm were the technology to develop a practical value to them. If the research outcome proves to be not commercially viable or not the prevailing technological paradigm, the relatively low costs of this strategy are not a matter of great concern. However, this is not an option that presents itself for smaller firms with limited resources. In addition, property rights protection is as yet undetermined - for instance, the question of cloning and gene manipulation research output is still an area of some controversy. Property right protection is thus achieved through secrecy, and collaborative research therefore is a risky option.

Where property rights are clearly defined, technical change is slow and uncertainty is low, (quadrant D), non-internal R\&D options are least risky - completely external technological outsourcing is feasible. Competitive advantage in these industries generally derives not from technology per se, where the products are 'generic', but from marketing and economies of scale. Indeed, firm E which is engaged in a natural-resource extracting sector, explained:

"We have nothing to hide. We believe in sharing all our technologies, because we don't really have anything special. There isn't much that our competitors don't already have, and its really a small circle - everyone knows everyone else - we have all been in this industry a long time. Things change very slowly, and we make most of our profits from downstream activities. Maybe our core asset is our marketing and logistics department."

Indeed, with very low R\&D intensities, much of the research by such companies is done with universities, and in collaboration with equipment suppliers. Another firm E manager explained,

"If there is a new environmental standard, its good for us. We have to design new machinery or adapt existing equipment for our major customers. It means more orders. But it also means we have to make the R\&D investment. If we don't, a competitor will, and they will 
get all the orders. Margins are tight, because we have a long-term relationship, so we never question the wisdom [of subsidising the R\&D of customers]. "

The need for alliances and more formal interaction between buyers and suppliers, then, is considerably reduced, since a high level of trust and interdependence exists. Likewise, because technology changes only very slowly, quick response alliance modes such as nonequity agreements are not at all popular (Hagedoorn and Narula 1996). As such, outsourcing is often the most preferred option. Figure 8 summarises the decision tree for quadrant D industries.

*******FIGURE 8 ABOUT HERE*******

\section{Some conclusions, caveats and avenues for future research}

This paper has tried to develop an understanding of some of the technological and economic factors that underlie how firms choose between in-house $R \& D, R \& D$ alliances and outsourcing. We have develop our framework along two lines. First, we have examined how firms choose between these three modes in a static situation. That is, given a firm's distribution of competencies, and the availability of alternatives, it is possible to determine, ceteris paribus, which technologies will be undertaken in-house, and for which technologies firms are more likely to use non-internal means. We have used some anecdotal data based on interviews to lend support to our framework. There is, of course, considerable variation between technologies, depending upon whether they are pre-paradigmatic, paradigmatic or post-paradigmatic. In addition, technologies evolve over time, and new innovations external to the firm may have to be absorbed, and utilised within the existing technological portfolio of the firm.

Thus, our second objective has been to develop a framework that examines these dynamic issues, based in part on the pioneering efforts of Teece $(1986,1996)$. We have argued that the choice between these three organisational modes varies with the maturity of the technological paradigm and the distribution of technological competences of the firm. In addition, as changes take place in the maturity of the technology, the choice of mode will change. Furthermore, new technologies may be introduced into the firm's portfolio of competencies, and the choice of mode is also determined by its having a systemic or an autonomous effect on the firms existing technologies.

Obviously, firms are path-dependent, and idiosyncratic. We do not claim that our analysis is by any means exhaustive, or necessarily more than guidelines about how firms 
might behave when it comes to decisions about non-internal R\&D activities. We would go so far as to say that our analysis and discussion simply points towards some general trends, rather hard and fast rules about the choices open to firms.

Indeed, in developing our discussion, we are only too aware of the large number of caveats that apply to our models. There are numerous strategic and economic issues that have not been included in our arguments, strongly supported by anecdotal information acquired from the interviews. We shall endeavour to highlight some of these here, which need to be considered in future work.

Perhaps the single most important variable that seems to be ignored in much of the literature, is the issue of firm size, and the consequent limited resources these firms are able to invest in $R \& D$. The pressure to innovate and to master multiple technologies applies to firms of all sizes. Clearly, outsourcing and alliances provides an opportunity for small and medium sized enterprises (SMEs) to have access to capabilities they ordinarily might not be able to afford, or to justify a higher-than-industry-average R\&D intensity to top management. This use of outsourcing to 'smooth out' cyclical variations in demand has been noted also by Buckley and Chapman (1998: 373). As Firm C noted,

"building up [research capacity in a new area] takes time. 1-2 years to hire 5-6 qualified researchers, and to work as a team. It is justifiable when times are good, but we can't just lay researchers off when times are hard. We have to keep them on, or we demoralise the whole department."

This strategy, it should be noted, was used by large companies too. Firm D noted of its customers,

"They use us as a valve. When times are good, they give us more design projects, and more orders. When times are hard, we are told to cut costs [before they do]."

Indeed, SMEs may utilise non-internal means to a greater extent than large firms, not just because it allows them to have access to and/or master new technologies, but also because they themselves are often dependent on larger firms as customers. Large firms have the resources to commercialise production of products and processes involving new technologies, and can afford the high capital costs needed to achieve the necessary market penetration, since the marginal cost of using their existing facilities is low. Small firms often have no choice to be involved in close-knitted alliances with large firms. Although our data is by no means representative, SMEs tend to engage in fewer horizontal alliances with other SMEs. 
It should be noted that there is a lower limit to the extent to which any firm (but particularly SMEs) can use non-internal sources as a substitute for internal R\&D. Both alliances and outsourcing require complementary resources. Some level of in-house capacity is essential to absorb the externally acquired information. Furthermore, alliances in particular require considerable managerial resources, not just because of the collaborative aspect, but also because alliances tend to be used where technology is tacit

Firms also determine their R\&D strategies based on purely strategic rationale, in order to improve their long-term product-market positioning. We suggest four of the more important reasons. First, as Kay (1997) explains, 'it is necessary to engage in networks with certain firms not because they trust their partners, but in order to trust their partners' (Kay 1997: 215). When companies decide to seek cost-savings in an innovatory process (or any other high cost/high risk project), its makes sense to do so with a partner with whom no freerider dangers exist. In other words, although it is impossible to be certain about the outcome of an alliance, there is a higher probability that where trust has been created in a previous alliance, the new alliance is more likely to be successful.

Second, there is the follow-the-leader strategy, as originally highlighted by Knickerbocker (1973). Firms seek partnerships in response to similar moves made by other firms in the same industry, not always because there are sound economic rationale in doing so, but in imitation of their competitors.

Third, firms sometimes partner with unknown partners with uncertain or unproven technologies rather than successful players. Why would a potential partner wish to collaborate with another which has limited or as-yet-undemonstrated resources to offer?

i. because of the nature of innovation, the only way to determine the nature of a potential partner's research efforts is to examine them. One way it can do so is by engaging in some form of mutual hostage exchange, which an alliance provides.

ii. even where the partner's resources prove to be of a limited or inappropriate nature, and the alliance is terminated prematurely, information about its former partner's competencies are then available to either firm in future periods, should it require competencies similar to those on offer by its ex-partner.

iii. as Hagedoorn and Duysters (1997) have argued, while selecting partners that are well-established players in existing technologies may represent profit maximising situation, it is optimal only in a static environment. In a dynamic environment, where there is a possibility of technological change (or even a 
change in technological trajectories), having ties to a wide group of companies, including companies that have yet to demonstrate their value, represents a higher learning potential.

Fourth, the high rate of failure of alliances and their inherent instability (Inkpen and Beamish 1997) means that it is a good idea to have redundant agreements - not all agreements will be successful for all parties concerned, and in addition to allowing firms to discover what cards their competitors have up their sleeves, it permits them to 'learn about learning' and the art of managing alliances.

We have not discussed the differences in types of partners, and how this may effect the choice between internal and external $R \& D$. Universities, for instance, are regarded in a different way in terms of trust than commercial enterprises. Firms often undertake more 'sensitive' research at arms-length with universities than with other firms. However, this may simply reflect the tendency for firms to undertake more basic (and therefore tacit) activity with universities. Tidd and Trehwalla (1997), for instance, observe that universities are the most widely used external source of technology, although this may varies quite considerably across countries (Granstand 1998), and across industries.

All these issues are important, and deserve far more attention than has been given here. Nonetheless, we feel that the two frameworks developed here allow both firms and policy makers to consider the significance of the options available to them. In addition, they can be useful in assisting in making more rational decisions, and to evaluate the implications of the type of R\&D investment, in addition to the amount of investment, on long term competitiveness. 


\section{Appendix A}

The anecdotal evidence cited here derives from a larger ongoing survey being conducted on the internationalisation of R\&D by European based MNEs. Currently, over 100 firms have been surveyed, through mailed questionnaire surveys and 32 firm interviews. The criteria for selection of these firms has been a) That they were majority-European owned as of 1998, b) engaged in manufacturing, c) have annual $R \& D$ expenditures greater than (approximately) US\$1 million and/or 10 full-time R\&D employees. All interviews were conducted with the head of the R\&D department or vice-president of technology development, or equivalent. In case of multi-divisional firms, interviews were conducted with several divisions, and occasionally from various levels. Detailed information on internal and external activities were not collected through the questionnaire survey, which was undertaken during 1998, and was only undertaken during the interviews, conducted after the survey. In all interviews, without exception, the interviewees expressed concern about the sensitive nature of the information provided, and have insisted on confidentiality. Therefore, given the relatively small sample size, and the very specific nature of their products and competences, and the small number of firms in each industry, it is difficult to give statistical overview regarding our sample, without breaching confidentiality.

We have used the interview material along the lines of a unorthodox case-study analysis to illustrate our arguments, by amalgamating firms that have similar technological activities into fictitious firms, so as to prevent any single firm from being identified. We give a brief overview of these here. We have attempted to match 'similar' firms together, in terms of technology intensity, primary technologies, size and distribution of international activities, but not nationality, structure of ownership or age of firms. In addition, some amalgamations include a division of a large multinational conglomerate. In such cases, we have excluded certain details which might reveal the identity of the parent firm, and therefore the firm in question.

We use the terms alliances and outsourcing as understood and used in relation to the MERITCATI database (see Narula and Hagedoorn 1999). By outsourcing we take to mean agreements that are more arms-length in nature, where active collaboration does not take place. There is generally a clear customer-supplier relationship, and no joint innovative activity takes place, although coordination for systems integration may be undertaken. Alliances are taken to be agreements where there is a clear, significant, and systematic 
interdependence between the parties involved, with both firms undertaking innovative activities.

\section{Firm A}

Medical equipment manufacturer (amalgam of 2 firms). 400-700 employees, 40-70 R\&D employees. No overseas production, centralised R\&D activities. Both firms are industry-leaders in their products.

\section{Firm B}

Measurement and industrial control equipment (amalgam of 4 firms). - between a 800 and 2000 employees, 40-100 employees in R\&D department. Centralised R\&D facilities. All four companies have a dominant position in their market segment (varying from $15 \%$ to $60 \%$ of world-wide market share in their market segment).

\section{Firm C}

Transportation equipment component manufacturer (amalgam of 3 companies). Primarily supplies sub-assemblies to three or four major manufacturers. R\&D department of division between 100 and 200 employees. Part of a large transportation equipment manufacturer. Overall employee number is confidential.

\section{Firm D}

Office equipment manufacturer, sells under its own brand name, no OEM activity (amalgam of 2 companies). One primary product range, $R \& D$ activity in several countries, between 400 and 1000 R\&D employees. Both firms are among top-three players in their industry

\section{Firm E}

Resource-intensive firm (amalgam of 4 companies). Includes 2 paper and wood products companies and two metals industries firms (fabrication divisions excluded). All firms included are large (greater than 5000 employees) 


\section{REFERENCES}

Abernathy, W. and Utterback, J (1978) patterns of industrial innovation, technology review, Vol 80, pp97-107

Archibugi, D. and Iammarino, S. (1999) The policy implications of the globalisation of innovation, Research Policy, Vol 28, pp 317-336

Arora, A. and Gambardella, A (1990) complementarity and external linkages: the strategies of the large firms in biotechnology, Journal of Industrial Economics, vol 37, pp 361-379

Arundel, A. and Kabla, I. (1998) What percentage of innovations are patented? Empirical estimates for European firms, Research Policy, Vol 27, pp 127-141

Benito, Gabriel (1997), Divestment of foreign production operations, Applied Economics, Vol. 29, no. 10, pp. 1365-1377

Buckley, P. and Casson, M. (1998) Models of the multinational enterprise, Journal of International Business Studies, Vol 29, No 1, pp

Buckley, P. and Chapman, M. (1998) The management of cooperative strategies in R\&D and innovation programmes, International Journal of the Economics of Business, Vol. 5, pp 369-381

Cantwell, J. and Santangelo, G. (1999) The frontier of international technology networks; sourcing abroad the most highly tacit capabilities, Information Economics and Policy, pp 101-123

Cohen, W. and Levinthal, D (1990) Absorptive capacity; a new perspective on learning and innovation, Administrative Science Quarterly, Vol 35, pp 569-596

Cowan, Robin and Dominique Foray, (1997) The Economics of Codification and the Diffusion of Knowledge Industrial and Corporate Change, vol. 6(3), pp.595-622

Croisier, (1998) The governance of external research: empirical test of some transaction-cost related factors, R\&D Management, Vol 28, pp 289-298 
Culpan, R. and E. Kostelac (1993) Cross national corporate partnerships: trends in alliance formation, in R. Culpan (ed) Multinational Strategic Alliances, International Business Press, New York, pp103-122

Cyert, R.M. and J.G. March (1963), A behavioral theory of the firm, Englewood Cliffs, Prentice-Hall.

David, P. (1985) 'Clio and the economics of QWERTY' American Economic Review, Vol 75, no 2, pp 332-7

Dosi, G (1982) 'Technological paradigms and technological trajectories: a suggested interpretation of the determinants and directions of technical change', Research Policy 11: $147-62$

Edquist, C. (1997) Systems of Innovation, London: Pinter

Gambardella, A. and Torrisi, S. (1998) "Does Technological Convergence imply Convergence in Markets? Evidence from the Electronics Industry", Research Policy,

Granstand, O. (1998) towards a theory of the technology based firm, Research Policy, Vol 27, pp 465-490

Granstrand, O. and Oskarsson, C. (1994) "Technology Diversification in 'Multi-Tech' Corporations", IEEE Transactions on Engineering Management, 41: 355-364.

Granstrand, O., and Sjolander, S.(1990) "Managing Innovation in Multi-technology Corporations", Research Policy, 19:35-60.

Granstrand, O., Patel, P. and Pavitt, K. (1997) "Multi-Technology Corporations: Why They Have "Distributed" Rather Than "Distinctive Core" Competencies", California Management Review, Summer 1997, Vol. 39, No. 4: 8-25

Gugler, P. and Pasquier, M. (1996) Strategic alliances of Swiss firms: theoretical considerations and empirical findings, Institut für Marketing und Unternehmungsführung Working Paper no 27

Hagedoorn, J. (1996) Trends and patterns in strategic technology partnering since the early seventies, Review of Industrial Organization, Vol 11, pp 601-616 
Hagedoorn, J. and Duysters, G. (1997) Satisficing strategies in dynamic inter-firm networksthe efficacy of quasi-redundant contacts, MERIT working paper series 97-016

Hagedoorn, J. and Narula R. (1996) Choosing Modes of Governance For Strategic Technology Partnering: International and Sectoral Differences, Journal of International Business Studies Vol 27, pp 265-284

Inkpen, A. and Beamish, P. (1997) Knowledge, bargaining power, and the instability of international joint ventures, Academy of Management Review, Vol. 22, pp 177-202

Kay, N. (1997) Pattern in Corporate Evolution, Oxford: Oxford University Press

Knickerbocker, F.T. (1973) Oligopolistic reaction and the multinational enterprise, Cambridge (Mass.), Harvard University Press.

Levin, R., Klevorick, A., Nelson, R., and S. Winter (1987) Appropriating the Returns from Industrial Research and Development, Brookings Papers on Economics Activity, No 3, pp 783-820

Lowe, J. and Taylor, P. (1998) R\&D and technology purchase through license agreements: complementary strategies and complementary assets, R\&D Management, Vol 28, pp 263-278

Lundvall, B.(1992) National Systems of Innovation: Towards a Theory of Innovation and Interactive Learning, London, Pinter Publishers

Mitchell, W and Singh, K (1992) 'incumbents' use of pre-entry alliances before expansion into new technical subfields of an industry, Journal of Economic Behaviour and Organisation, Vol 18, pp347-372

Nagarajan, A. and Mitchell, W. (1998) Evolutionary diffusion: internal and external methods used to acquire encompassing, complementary, and incremental technological changes in the lithotripsy industry, Strategic Management Journal, Vol 19, pp 1063-1077

Narula, R. (1999) Explaining Strategic R\&D alliances by European firms, Common Market Studies, Vol 37, December, forthcoming 
Narula, R. and Hagedoorn, J. (1999) Innovating through strategic alliances: moving towards international partnerships and contractual agreements, Technovation, Vol. 19, pp 283294.

Nelson, R. and Winter, S. (1982) An Evolutionary Theory of Economic Change , Belknap Press, Cambridge

Pavitt, K. (1998) Technologies, products \& organisation in the innovating firm: What Adam Smith tells us and Joseph Schumpeter doesn't Industrial and Corporate Change, 7:433452

Sachwald, F. (1998) Cooperative agreements and the theory of the firm; focusing on barriers to change, Journal of Economic Behaviour and Organisation, Vol 35, pp 203-225

Teece, D. (1986) profiting from technological innovation: implications for integration, collaboration, licensing and public policy, Research Policy, Vol 15, pp 285-305

Teece, D. (1996) "Firm Organisation, Industrial Structure and Technological Innovation", Journal of Economic Behaviour and Organisation, 31: 193-224.

Teece, D. and Pisano, G. (1994) "The Dynamic Capabilities of Firms: an Introduction", Industrial and Corporate Change, 3:537-556.

Tidd, J. and Trewhella, M. (1997) Organizational and technological antecedents for knowledge creation and learning, R\&D Management, Vol 27, pp 359-375

Veugelers, R. (1997) Internal R\&D expenditures and external technology sourcing, Research Policy, Vol 26, pp 303-315

Veugelers, R. and Cassiman, B. (1999) Make and buy in innovation strategies: evidence from Belgian manufacturing firms, Research Policy, Vol 28, pp 63-80 


\begin{tabular}{|c|c|}
\hline $\begin{array}{l}\text { Quadrant II: background } \\
\text { competences }\end{array}$ & $\begin{array}{l}\text { Quadrant I: Distinctive } \\
\text { competences }\end{array}$ \\
\hline $\begin{array}{l}\text { Enables firm to coordinate and benefits } \\
\text { from technical change in supply chain }\end{array}$ & \\
\hline $\begin{array}{l}\text { High share of technological assets } \\
\text { Low level of competence }\end{array}$ & $\begin{array}{l}\text { High share of technological assets } \\
\text { High level of competence }\end{array}$ \\
\hline $\begin{array}{l}\text { Quadrant III: } \\
\text { marginal/peripheral } \\
\text { competences }\end{array}$ & $\begin{array}{l}\text { Quadrant IV: niche } \\
\text { competences }\end{array}$ \\
\hline May become important/were important & \\
\hline $\begin{array}{l}\text { Low share of technological assets } \\
\text { low level of competence }\end{array}$ & $\begin{array}{l}\text { Low share of technological assets } \\
\text { High level of competence }\end{array}$ \\
\hline
\end{tabular}

Source: based on Granstand, Patel and Pavitt (1996)

Figure 1: The distribution of a competences 


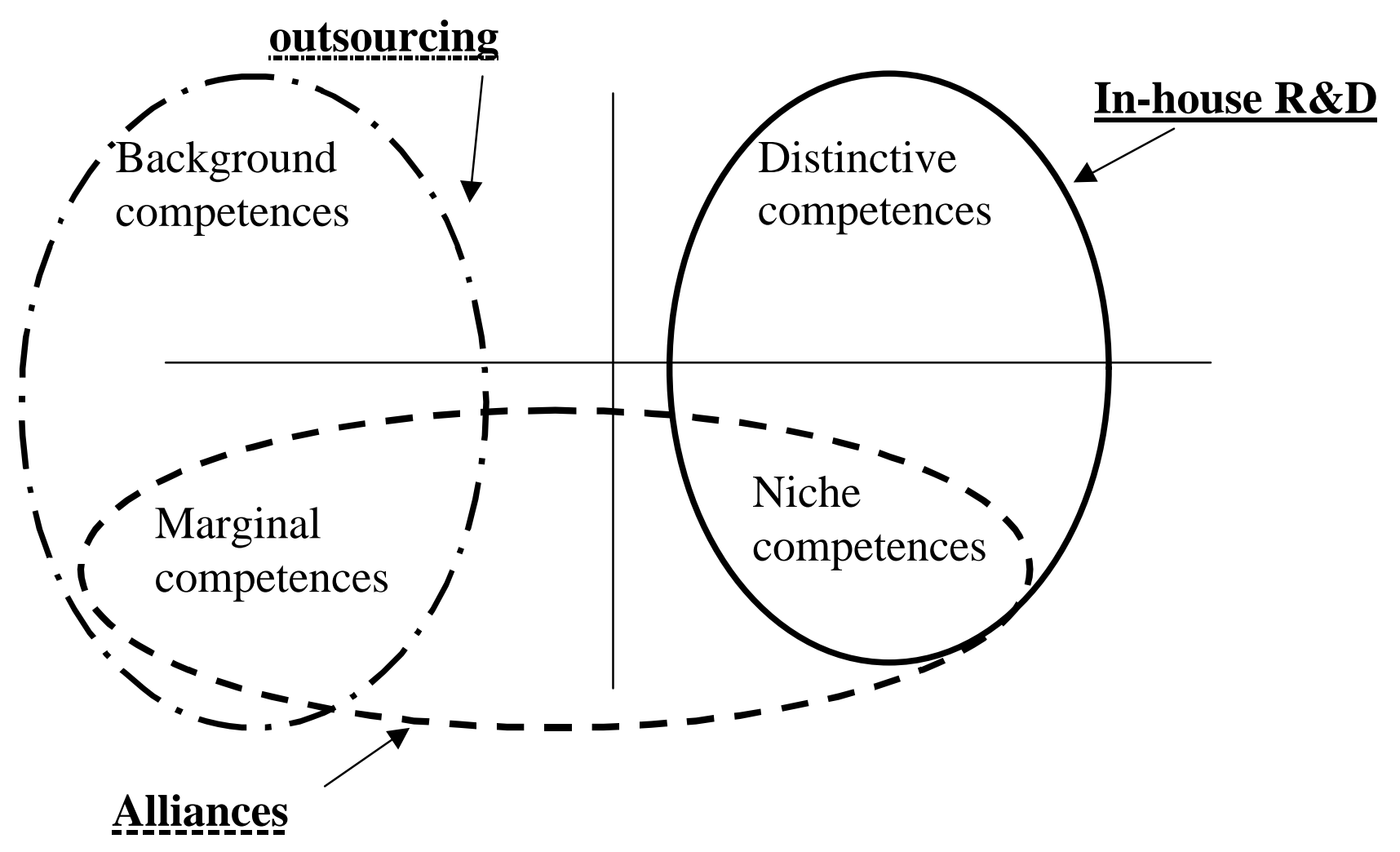

Figure 2: The static view: relationship between distributed competences and internal/non-internal R\&D 


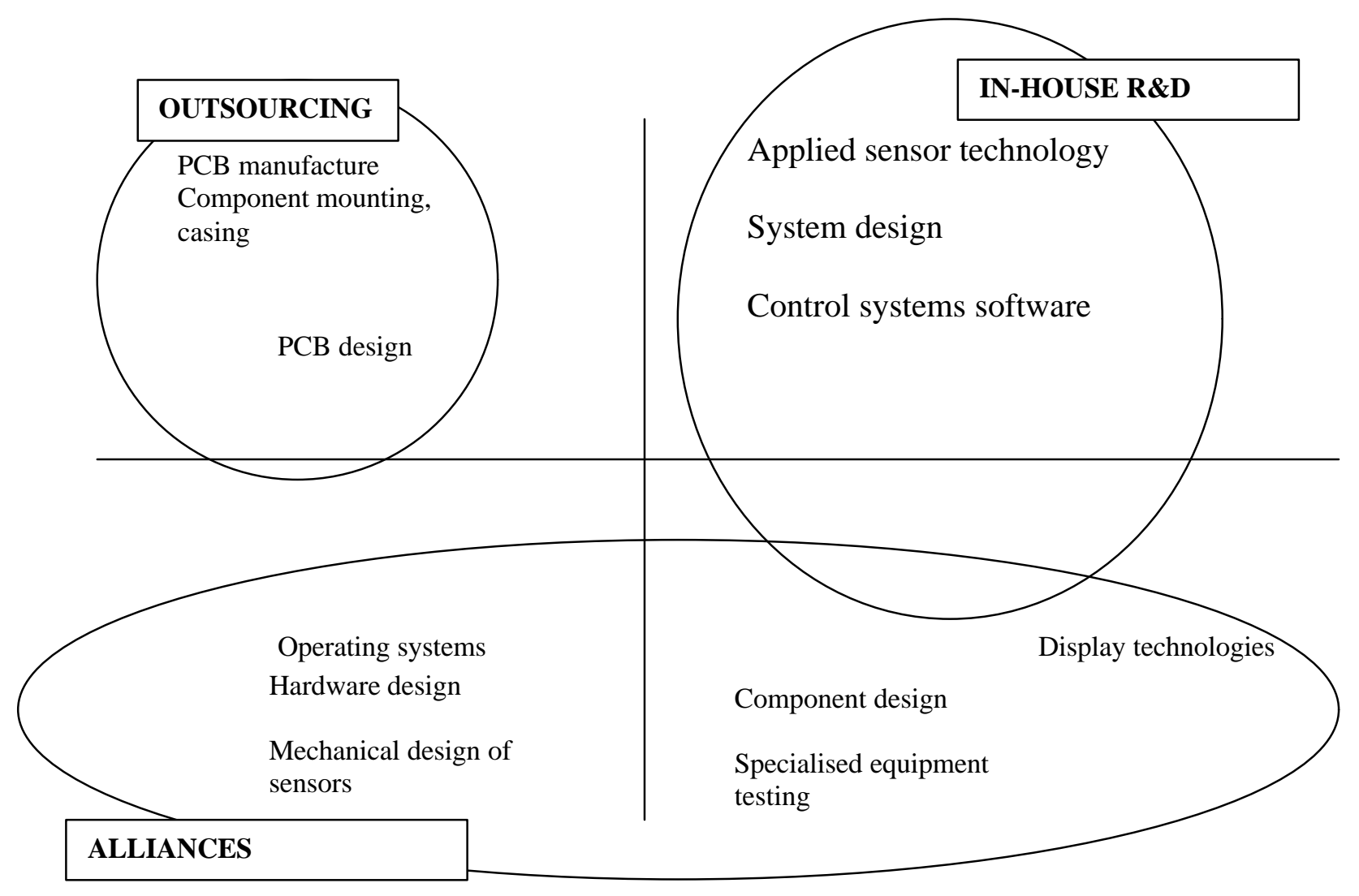

Note: No attempt has been made to locate technologies on a relative basis within any given quadrant.

Figure 3 Distribution of competences of firm B, based on managers' perceptions 


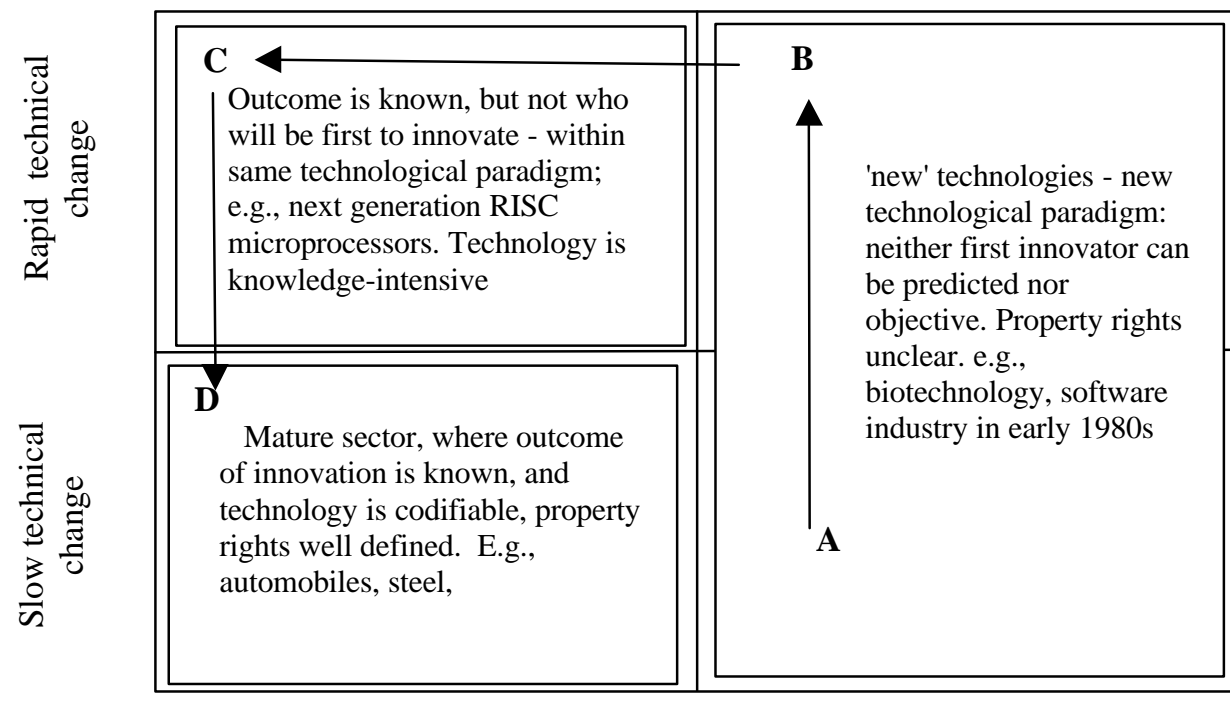

Low uncertainty

High uncertainty

Figure 4: Technological evolution with a given paradigm 


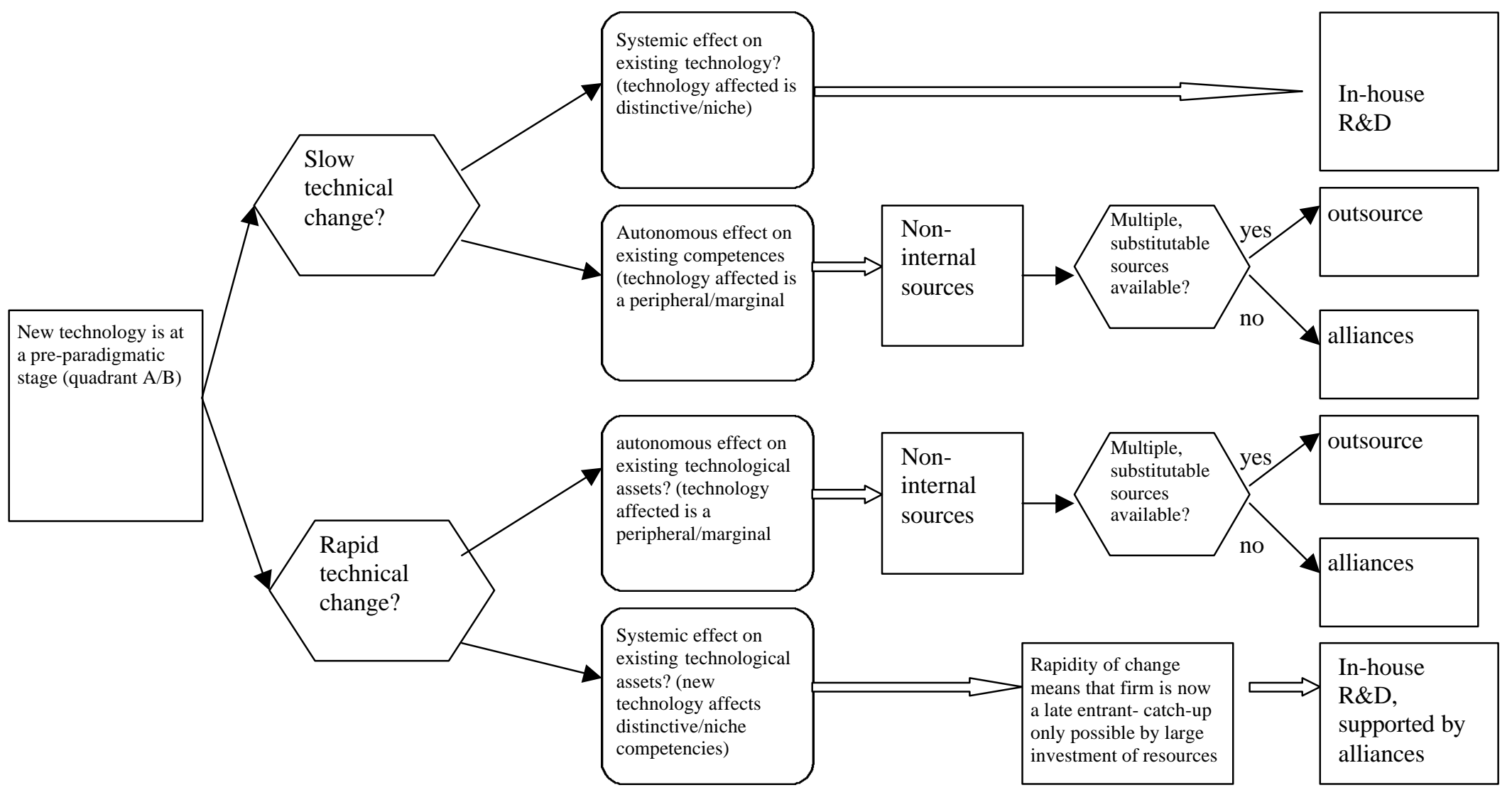

Figure 5 - decision tree in selecting mode of R\&D for pre-paradigmatic technology 


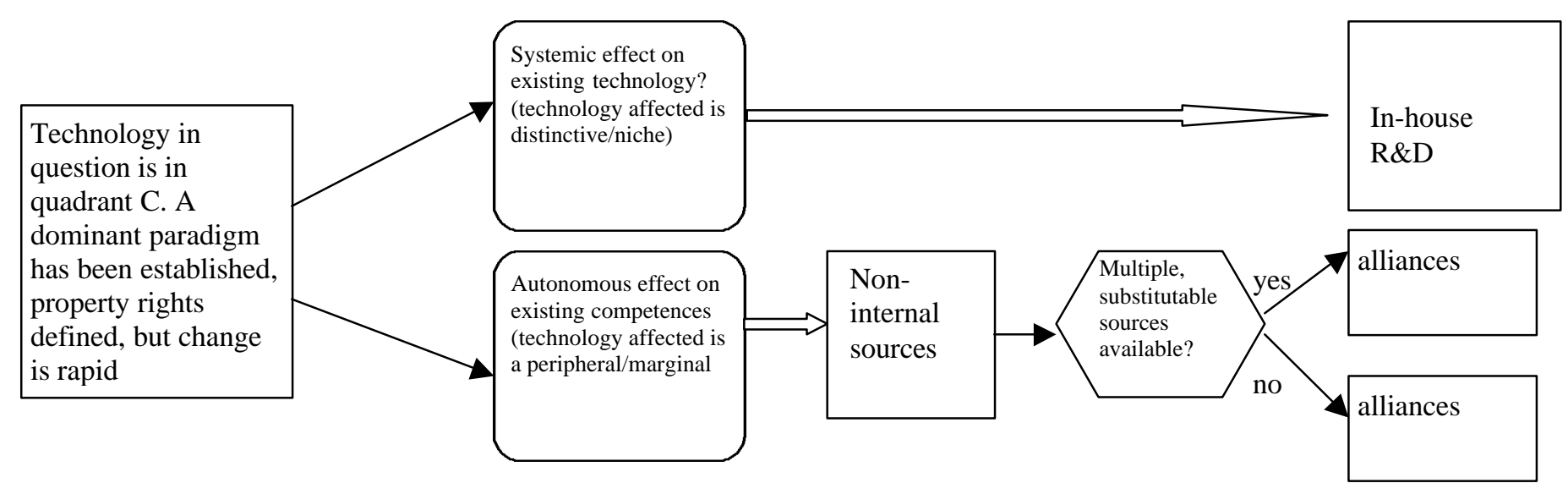

Figure 6 - decision tree in selecting mode of R\&D for paradigmatic technology 


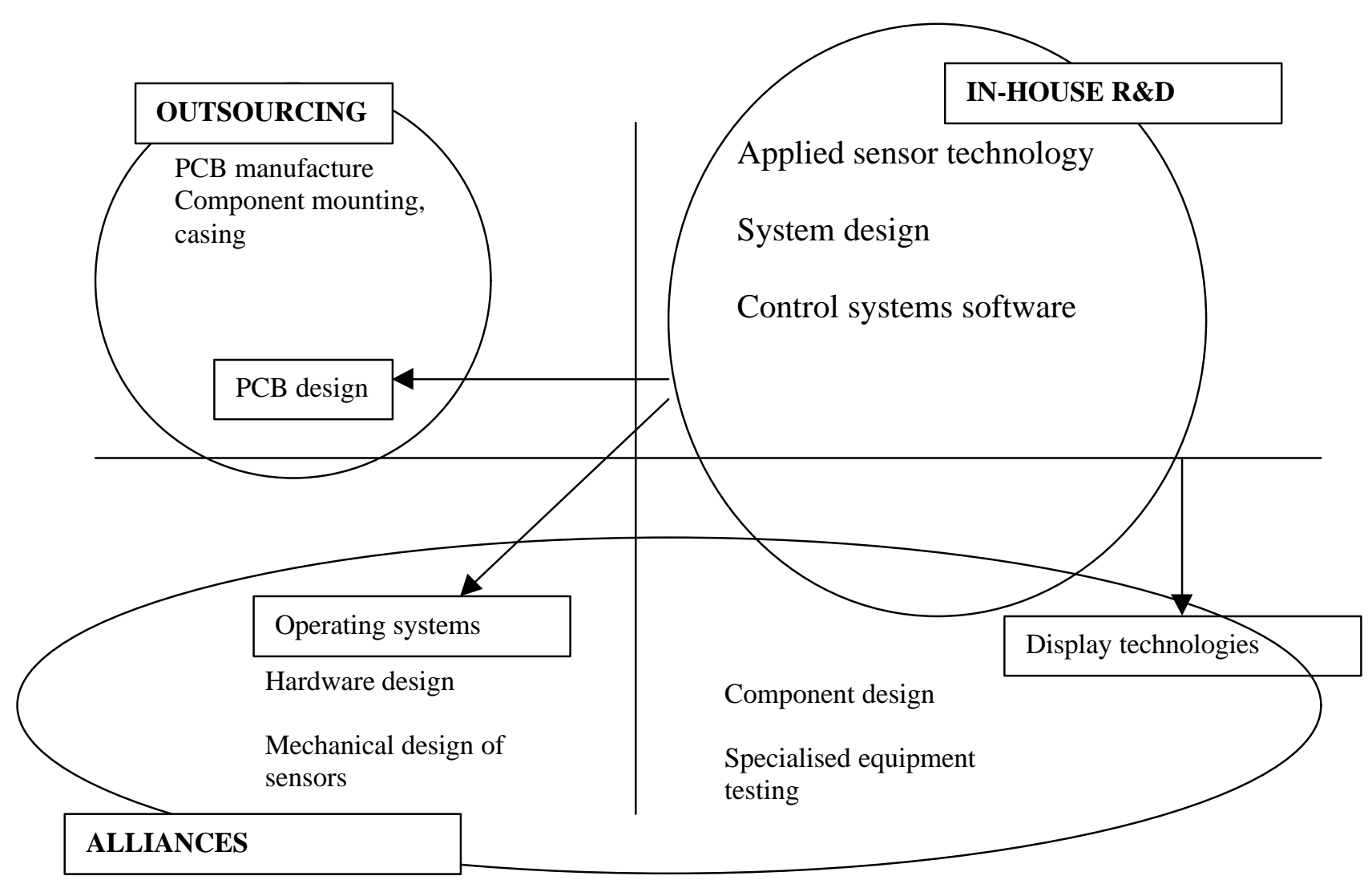

Note: No attempt has been made to locate technologies on a relative basis within any given quadrant.

Figure 7: How the significance of technologies changes over time 


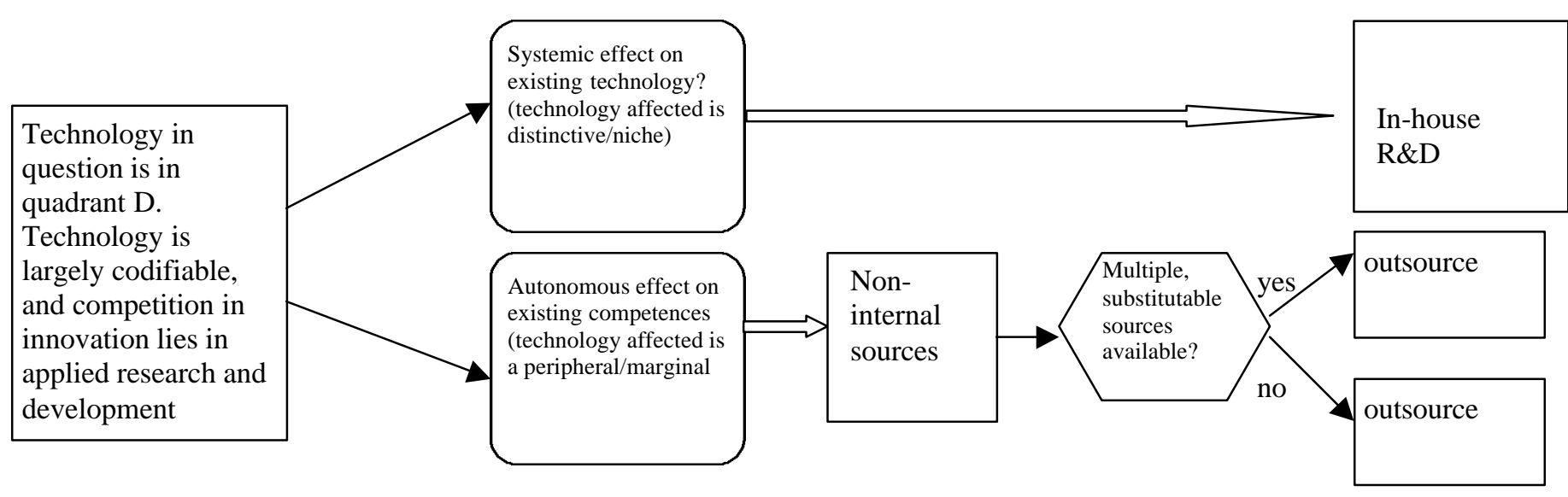

Figure 8 - decision tree in selecting mode of R\&D for post-paradigmatic technology 